\title{
Gender Differences in the Use of Hedges And First Person Pronouns in Research Articles of Applied Linguistics and Chemistry
}

\author{
Fatemeh Mirzapour (Corresponding author) \\ Department of English and Foreign Languages, Sofian Branch, Islamic Azad University, Sofian, Iran \\ E-mail: fdadashzadeh@yahoo.com
}

Received: 03-06-2016

Published: 01-11-2016
Accepted: 12-08-2016

doi:10.7575/aiac.ijalel.v.5n.6p.166
Advance Access Published: September 2016

URL: http://dx.doi.org/10.7575/aiac.ijalel.v.5n.6p.166

\begin{abstract}
Differences in the way that males and females use language have been of interest in the study of discourse. This study is an attempt to examine whether men and women differ with respect to the use of hedges and first person pronouns in research articles of two disciplines of Applied Linguistics and Chemistry. Based on a corpus of sixty research articles, the overall categorical distribution of hedging devices and first person pronouns were calculated in research articles. The results indicate that hedges and first person plural pronouns are used in Applied Linguistics articles more frequently than Chemistry articles. Moreover, females use hedges more than males in both disciplines but males use first person plural pronoun more than females in both disciplines. These findings may have some implications for the teaching of academic writing to EFL students.
\end{abstract}

Keywords: Gender, Hedges, Person Pronoun, Research Articles

\section{Introduction}

Females and males' differences are related not only to the nature of their psychology and physiology but also to their use of language. Lakoff (1975) claimed in her book Language and Women's Place that 'women language' is different from 'men's language'. She argued that women's language included features such as the use of polite forms, the use of question tags, rising intonation in declarative, the avoidance of expletives, and the use of more hedges. Lakoff's book led to two separate views of women's language, namely the 'difference approach' and 'dominance approach'. ' Dominance approach' is the study of power differences and focuses on unequal roles as the source difference (Schiffrin, et al. 2001). This approach sees women's language as the reflection of women's subordinate position in society.

According to 'difference' or 'cultural approach', men and women are part of different subcultures because they are from different social and ethnic background. Therefore, males and females grow up learning different ways of using language (Paltridge, 2006).

'Deficit' is another approach discussed in Cameron (1998). According to this approach women's language is deficient in certain respects 'by nature or by nurture'. In 1970 feminists criticized this view and argued that this theory was biased account in favor of men's language.

In a critique of these views of language and gender Cameron (2005) argues that gender is socially constructed and gender is 'not something a person "has", but something a person does' (Cameron, 2005: 49). The relationship between language and gender is not direct and is mediated by something else.

1.1 Research objectives

The current study pursues the following main objective:

- To investigate whether the use of hedges and first person pronouns in research articles of two disciplines of Applied Linguistics and Chemistry differs between men and women.

1.2Empirical evidence of gender differences in spoken and written language

Gender as a social variable has an important role in language use. Gender differences in language use became the focus of attention since 1970. For example, Robin Lakoff (1975) identified ten features in women's language including: lexical hedges or fillers (e.g. you know, sort of, ...), tag questions (e.g. ... isn't it?,...), rising intonation on declaratives (e.g. it's really good,...), empty adjectives (e.g. cute, charming, ...), intensifiers (e.g. just, so,...), hypercorrect grammar (e.g. consistent use of standard verb forms,...), super polite forms (e.g. indirect requests,...), avoidance of strong swear words (e.g. my goodness,...), and emphatic stress (e.g. it was BRILLIANT performance,...). Trudgill (1976) carried out a study in Norwich to examine how men and women pronounce non-standard form of (ing) in ing-ending words. It was found that females used more standard forms than males. Holmes (1993) mentions that different words with the same meaning are used distinctively by males and females in Japan. Mulac and Lundell (1994) claimed that uncertainty verb phrases, especially those combining first-person singular pronouns with perceptual or cognitive verbs( e.g., "I 
wonder if ") have been found more often in women's language. Climate (1997) believes that women use speech to develop and maintain social relations. Mehl and Pennebark (2003) also reported that women were more likely to use first-person singular. Hota, Koppel and Zigdon (2006) carried out a corpous-based study on gender differences in Shakespeare's play. Greater stylistic difference between males and females in the late Shakespeare's play than in early one was found.

Tse and Hyland (2004) argued female's discourse as more rhetorically elaborated, interactive but male's discourse as more assertive, personally neutral and challenging style.

In recent decades research articles as a formal academic written genre have been the focus of attention. They are studied cross-linguistically (among different languages), cross-disciplinary and just marginally with respect to gender (Vold, 2006). Among many variables that could be used to examine gender differences are hedging words and first person pronouns. These two features are studied cross-linguistically and cross-disciplinary (Varttala, 1999; Vold, 2006) but little attention was paid to cross-gender. In other words, hedging words and first person pronouns were studied across different disciplines. It was found that first person plural pronoun "we" was used very frequently in the research articles of disciplines belonging to the social sciences including: Management, Applied Linguistics, and Marketing than (Hyland, 2001; Millan, 2010). Moreover, hedging words were analyzed in research articles from different disciplines. It was also found that hedging words were employed with high frequency in research articles belonging to social sciences as Psychology, Economics, philosophy, Marketing, and Applied Linguistics than hard science disciplines such as Chemistry, Engineering, and Biology (Hyland, 1996; Varttala, 2001; Falahati, 2006).

This study tries to compare males and females research articles through the investigating hedges and first person pronouns in two disciplines of Applied Linguistics and Chemistry. The importance of hedges as the textual precision and interpersonal relationship has been emphasized by some scholars like Varttala (2001). Moreover, comparing the distribution and frequency of hedges between male and female document is addressed by some scholars (Vold, 2006; Afros, 2007; Khalilzadeh, 2008). Hyland (2002) argues that academic writing is not a faceless and impersonal discourse. Hyland (2002: 352) is of the opinion that "almost everything we write say something about us and the sort of relationship that we want to set up with our readers". Through the use of the pronoun "I" expert writers do this. Millan (2010) argues that “ in today's academic world, creating a suitable authorial identity by means of self-mention resources is essential to project an image of competence and reliability in research articles and to highlight the relevance of one's contributions. According to Hyland (2001, 2002), the way writers use self-mention resources to construct their authorial self can vary depending on the social norms of each disciplines. In his view, showing the appropriate degree of authorial presence is one way to signal membership to a particular community of scholars.

The main research questions addressed in this study were:

1) Is there difference between the frequency of occurrence of hedges and first person pronouns in the research articles in the fields of Applied Linguistics and Chemistry?

2) What is the frequency of the kinds of hedging and first person pronouns in the research articles in the fields of Applied Linguistics and Chemistry?

3) Is the frequency of occurrence of hedges and first person pronoun the same between the research articles written by males and females in the field of Applied Linguistics?

4) Is the frequency of occurrence of hedges and first person pronoun the same between the research articles written by males and females in the field of Chemistry?

5) Is the frequency of occurrence of hedges and first person pronoun the same between the research articles written by males and females in the field of Applied Linguistics and Chemistry?

6) What is the frequency of the kinds of hedging and first person pronouns in the research articles written by males and females in the field of Applied Linguistics and Chemistry?

These research questions gave way to two null hypotheses as follows:

1) There is no significant difference between the frequency of occurrence of hedges and first person pronouns in the research articles in the fields of Applied Linguistics and Chemistry.

2) There is no significant difference between the frequency of occurrence of hedges and first person pronouns written by males and females in the research articles in the fields of Applied Linguistics.

3) There is no significant difference between the frequency of occurrence of hedges and first person pronouns written by males and females in the research articles in the fields of Chemistry.

4) There is no significant difference between the frequency of occurrence of hedges and first person pronoun in the research articles written by males and females in the field of Applied Linguistics and Chemistry.

\section{Research Method}

\subsection{Data for the study}

The data for this study consists of sixty research articles, thirty research articles belonging to Applied Linguistics and thirty research articles belonging to Chemistry. Among thirty articles in each disciplines, fifteen articles belong to male authors and fifteen articles belong to female authors. Research articles were drawn from the leading journals of Applied Linguistics and Chemistry published between 2006-2011. It was tried that the length of articles to be between 15-20 pages in each discipline. The selected articles were single-authored because the aim is to examine gender differences in using hedges and first person pronouns. For the purpose of the study, all footnotes, quotations, bibliographies, linguistic examples, tables and figures which appeared in the research articles were deleted from the data.

The research articles of two disciplines in this study were selected based on some criteria. The first criterion was having the Abstract, Introduction, Discussion, and Conclusion sections. The next criterion was the date of research 
article publication. The research articles were all limited to those published within the last five years. Articles written only by a single author were selected in each disciplines.

2.2 Procedures of Data Analysis

The main purpose of this study is to examine the gender differences in the use of hedging words and first person pronouns in two disciplines of Applied Linguistics discipline and Chemistry discipline. In order to meet this goal, sixty research articles were analyzed. Varttala's (2001) classification of lexical devices expressing hedging was used to determine the frequency of hedges in the articles of both disciplines. This classification consists of five main types of Modal auxiliaries, Full verbs, Adjectives, Adverbs, and Nouns Modal verbs expressing hedges are can, could, may,...; lexical verbs expressing hedges are appear, interpret, seem, suppose, suggest, think,...; adverbs indicating hedges are about, frequently, mostly, often, primarily, rarely, strongly, vastly,...; adjectives expressing hedges include apparent, common, main, major, small, usual,...; nouns expressing hedges are claim, idea, likelihood, suggestion, view,... . Six first person pronouns and possessive adjectives including $I, m y$, me, we, our, us were used for the investigation of first person pronouns.

In order to identify hedges and person pronouns, research articles were examined by the researcher and all the potential hedges and person pronouns were identified and noted down. Later, every instance of the identified words was analyzed contextually in order to determine whether interpretation of hedges was possible or not because no expression can always be said to function as a hedge in isolation; therefore, the consideration of context is essential. The results were then analyzed by means of Chi-Square test to see whether there is a significant statistical difference between these two disciplines in the distribution of hedges and person pronouns.

\section{Results}

In order to see if there is a significant difference between the frequency of occurrence of hedges and first person pronouns in the research articles in the fields of Applied Linguistics and Chemistry, the total number of hedges and first person pronouns and their percentage over the total number of running words in each field is computed and presented in table 1 .

Table 1. Frequency and percentage of hedges and first person pronouns in applied linguistics and chemistry

\begin{tabular}{lll}
\hline Category & Field & \\
\cline { 2 - 3 } & Applied Linguistics & Chemistry \\
\hline Hedges & 4246 & 2898 \\
& $35.68 \%$ & $24.91 \%$ \\
\hline First Person Pronouns & 148 & 113 \\
& $12.43 \%$ & $9.71 \%$ \\
\hline
\end{tabular}

The results in table 1 show that the use of hedges and first person pronouns constitute $35.68 \%$ and $12.43 \%$ of the total number of words in applied linguistics research articles respectively, whereas in chemistry research articles their use constitutes $24.91 \%$ and $9.71 \%$ of the total number of words respectively.

To answer the first research question, Chi-Square test was applied and the result is shown in table 2.

Table 2. Chi-Square test for the frequency of hedges and first person pronouns in applied linguistics and chemistry

\begin{tabular}{lll}
\hline & Hedge & First person pronoun \\
\hline Chi-Square & 3.200 & 63.550 \\
\hline df & 1 & 1 \\
\hline Asymp. Sig. & .000 & .001 \\
\hline
\end{tabular}

According to table 2, there is a significant difference between the frequency of occurrence of hedges in the research articles in the fields of Applied Linguistics and Chemistry $(x=63.550, p=.000, p<0.05 \quad)$. There is also a significant difference between the frequency of occurrence of first person pronouns in the research articles in the fields of Applied Linguistics and Chemistry $(x=3.200, p=.001, p<0.05)$. Therefore, the first null hypothesis is rejected.

The frequency and distribution of five kinds of hedges and six kinds of first person pronouns between the two disciplines are presented in table 3 and 4 respectively.

Table 3. Frequency and percentage of five kinds of hedges in applied linguistics and chemistry Field

\begin{tabular}{lll}
\cline { 2 - 3 } & $\begin{array}{l}\text { Applied } \\
\text { Linguistics }\end{array}$ & Chemistry \\
\hline Modal Verbs & 962 & 870 \\
& $22.65 \%$ & $30.02 \%$ \\
\hline Lexical Verbs & 1191 & 659 \\
& $28.04 \%$ & $22.73 \%$ \\
\hline Adverbs & 948 & 680 \\
& $22.32 \%$ & $23.46 \%$
\end{tabular}




\begin{tabular}{lll} 
Adjectives & 792 & 534 \\
& $18.65 \%$ & $18.42 \%$ \\
\hline Nouns & 353 & 155 \\
& $8.31 \%$ & $5.34 \%$ \\
\hline Total & 4246 & 2898 \\
& $100.0 \%$ & $100.0 \%$ \\
\hline
\end{tabular}

According to table 3, the most frequently used hedging device in Applied Linguistics research articles is lexical verbs (28.04\%) followed by modal verbs(22.65\%), adverbs $(22.32 \%)$, adjectives $(18.65 \%)$, and nouns $(8.31 \%)$. Whereas, the most frequently used hedging device in Chemistry research articles is modal verbs $(30.02 \%)$ followed by adverbs $(23.46 \%)$, lexical verbs $(22.73 \%)$, adjectives (18.42\%), and nouns $(5.34 \%)$.

Table 4. Frequency and percentage of six kinds of first person pronouns in applied linguistics and chemistry Field

\begin{tabular}{lll}
\cline { 2 - 3 } I & Applied Linguistics & Chemistry \\
\hline Me & 0 & 5 \\
& $0 \%$ & $4.42 \%$ \\
\hline My & 0 & 0 \\
& $0 \%$ & $0 \%$ \\
\hline We & 0 & 2 \\
& $0 \%$ & $1.76 \%$ \\
\hline Us & 85 & 39 \\
& $57.43 \%$ & $34.5 \%$ \\
\hline Our & 0 & 0 \\
& $0 \%$ & $0 \%$ \\
\hline Total & 63 & 67 \\
& $42.56 \%$ & $59.29 \%$ \\
\hline
\end{tabular}

On the other hand, the most frequently used first person pronoun in Applied Linguistics research articles falls into "we" pronoun (57.43\%) but "our" in Chemistry research articles (59.29\%). In Applied Linguistics research articles these are followed by the pronoun "our" $(42.56 \%)$, and in Chemistry research articles by the pronoun "we" (34.5\%), pronoun "I" $(4.42 \%)$, and the pronoun "my" (1.76\%).

Table 5 shows the number of hedges and first person pronoun and their percentage for each gender in Applied Linguistics research articles.

Table 5. Frequency and percentage of hedges and first person pronouns used by males and females in applied linguistics research articles

\begin{tabular}{lll}
\hline & Gender & \\
\cline { 2 - 3 } & male & Female \\
\hline Hedge & 1951 & 2295 \\
& $33.52 \%$ & $33.74 \%$ \\
\hline First Person Pronoun & 148 & 65 \\
& $25.42 \%$ & $10.69 \%$
\end{tabular}

According to table 5, it can be observed that in Applied Linguistics research articles females' use of hedges constitutes $33.74 \%$ of the total number of words, whereas for males it is $33.52 \%$. Moreover, males' use of first person pronouns constitutes $25.42 \%$ of the total number of words, whereas for females it is $10.69 \%$.

The results of the Chi-Square test are presented in table 6.

Table 6. Chi-Square test for the Frequency hedges and first person pronouns used by males and females in applied linguistics research articles

\begin{tabular}{lll}
\hline & Hedge & First person pronoun \\
\hline Chi-Square & 5.224 & 55.497 \\
\hline df & 1 & 1 \\
\hline Asymp. Sig. & 1.000 & .000 \\
\hline
\end{tabular}


As it is shown in table 6 , there is not a significant difference between the gender of writers and the use of hedges in Applied Linguistics research articles $(x=5.224, p=1.000, p<0.05)$. On the other hand, there is a significant difference between the gender of writers and the use of first person pronouns in Applied Linguistics research articles $(x=55.497$, $\mathrm{p}=.000, \mathrm{p}<0.05)$, which means that males use more first person pronouns in Applied Linguistics research articles. Hypothesis 2 is rejected from the aspect of first person pronoun but not from the aspect of hedges. In order to find any significant difference between the gender of writers and the use of hedges and first person pronouns in Chemistry research articles, the number of hedges and first person pronoun and their percentage for each gender in this field is computed and presented in table 7.

Table 7. Frequency and percentage of hedges and first person pronouns used by males and females in chemistry research articles

\begin{tabular}{lll}
\hline & Gender & \\
\cline { 2 - 3 } & male & Female \\
\hline Hedge & 1228 & 1670 \\
& $18.67 \%$ & $33.03 \%$ \\
\hline First Person Pronoun & 81 & 32 \\
& $12.31 \%$ & $6.29 \%$ \\
\hline
\end{tabular}

As indicated in table 7, the percentage of hedges used by males and females in Chemistry is $18.67 \%$ and $33.03 \%$ respectively, but the percentage of first person pronouns used by males and females in Chemistry is $12.31 \%$ and $6.29 \%$ respectively.

The results of the Chi-Square test are presented in table 8.

Table 8. Chi-Square test for the Frequency hedges and first person pronouns used by males and females in chemistry research articles

\begin{tabular}{lll}
\hline & Hedge & First person pronoun \\
\hline Chi-Square & 4.324 & 35.387 \\
\hline df & 1 & 1 \\
\hline Asymp. Sig. & .001 & .000 \\
\hline
\end{tabular}

As table 8 reveals there is a significant difference between the gender of writers and the use of hedges in Chemistry research articles $(x=4.324, p=.001, p<0.05)$, which means that females use more hedges than males. Besides, there is a significant difference between the gender of writers and the use of first person pronouns in Chemistry research articles $(\mathrm{x}=35.387, \mathrm{p}=.000, \mathrm{p}<0.05)$, which means that males use more first person pronouns than females. So the third hypothesis is rejected.

Table 9 presents the frequency and percentage of hedges and first person pronouns used by males and females in the fields of Applied Linguistics and Chemistry research articles.

Table 9. Frequency and percentage of hedges and first person pronouns used by males and females

\begin{tabular}{lll}
\hline & Gender & \\
\cline { 2 - 3 } & male & Female \\
\hline Hedge & 3179 & 3965 \\
& $25.64 \%$ & $35.60 \%$ \\
\hline First Person Pronoun & 229 & 97 \\
& $18.4 \%$ & $8.7 \%$ \\
\hline
\end{tabular}

According to table 9 , research articles written by males contained $25.64 \%$ of occurrence of hedges, but in research articles of female writers $35.60 \%$ of occurrence is observed. On the other hand, research articles written by males contained $18.4 \%$ of occurrence of first person pronouns, whereas in research articles of female writers $8.7 \%$ of occurrence is observed.

The results of the Chi-Square test are presented in table 10.

Table 10. Chi-Square test for the Frequency hedges and first person pronouns used by males and females

\begin{tabular}{lll}
\hline & Hedge & First person pronoun \\
\hline Chi-Square & 4.997 & 46.671 \\
\hline df & 1 & 1 \\
\hline Asymp. Sig. & .010 & .005
\end{tabular}


According to table 10, the results of the Chi-Square test shows that the difference between the frequency of hedges used by males and females in the data is statistically significant $(x=4.997, p=.010, p<0.05)$. In other words, the results indicate that female writers use more hedges than males. The results also reveals that the difference between the frequency of first person pronoun used by males and females in the data is statistically significant $(x=46.671, p=.005$, $\mathrm{p}<0.05$ ). It means that males use more first person pronoun than females.

The frequency and distribution of five kinds of hedges and six kinds of first person pronouns in the research articles written by males and females in the fields of Applied Linguistics and Chemistry are presented in table 11 and 12 respectively.

Table 11. Frequency and percentage of five kinds of hedges in research articles written by males and females

\begin{tabular}{lll} 
& Gender & \\
\cline { 2 - 3 } & Female & Male \\
\hline Modal Verbs & 913 & 1148 \\
& $25.91 \%$ & $31.70 \%$ \\
\hline Lexical Verbs & & \\
\hline Adverbs & 807 & 814 \\
& $22.90 \%$ & $22.47 \%$ \\
\hline Adjectives & 824 & 804 \\
& $23.38 \%$ & $22.20 \%$ \\
\hline Nouns & 729 & 597 \\
& $20.69 \%$ & $16.48 \%$ \\
\hline Total & 250 & 258 \\
& $7.09 \%$ & $7.12 \%$ \\
\hline
\end{tabular}

According to table 11 the most frequent hedging device is modal verbs by both females and males $(25.91 \%$ and $31.70 \%$, respectively). For females, these are followed by adverbs (23.38\%), lexical verbs (22.90\%), adjectives $(20.69 \%)$ and nouns $(7.09 \%)$, whereas for males, modal verbs are followed by lexical verbs $(22.47 \%)$, adverbs $(22.20 \%)$, adjectives $(16.48 \%)$ and nouns $(7.12 \%)$.

Table 12. Frequency and percentage of six kinds of first person pronouns in research articles written by males and females

\begin{tabular}{lll}
\hline & Gender & Male \\
\cline { 2 - 3 } I & Female & 0 \\
& $8.69 \%$ & $0 \%$ \\
\hline Me & 0 & 0 \\
& $0 \%$ & $0 \%$ \\
\hline My & 1 & 0 \\
& $1.08 \%$ & $0 \%$ \\
\hline We & 30 & 59 \\
& $32.60 \%$ & $26.22 \%$ \\
\hline Us & 0 & 33 \\
& $0 \%$ & $14.66 \%$ \\
\hline Our & 53 & 133 \\
& $57.60 \%$ & $59.11 \%$ \\
\hline Total & 92 & 225 \\
& $100.0 \%$ & $100.0 \%$ \\
\hline
\end{tabular}

As the results show, the most frequent first person pronoun is "our" by both females and males $(57.60 \%$ and $59.11 \%$, respectively). For females, these are followed by "we" (32.60\%), "I" (8.69\%) and "my" (1.08\%), whereas for males, "our" is followed by "we" (26.22\%) and "us" (14.66\%).

Results indicated that there is significant difference in the use of hedges and person pronouns between two gender groups in both disciplines. Female authors used more hedges than male authors in expressing their claims and ideas. In both disciplines, male authors used possessive adjective "our" more frequently in creating their authorial identity. 


\section{Discussion}

So far, gender differentiation has been investigated mainly in spoken discourses. But written discourses in general and research articles of different disciplines in particular have been studied restrictively in this regard. So, this study was an attempt to fill the gap by investigating the difference between male and female authors in using hedging words and first person pronouns in Applied Linguistics and chemistry research articles. It was hypothesized that there is no difference between male and female authors in using hedging words and first person pronouns in Applied Linguistics and chemistry research articles. To meet the goal of this study four hypotheses need to be considered in attempting to explain the results.

The difference between the frequency of occurrence of hedges and first person pronouns in the research articles in the fields of Applied Linguistics and Chemistry was examined in the first question. As the results of the first hypothesis indicated, the two disciplines showed some noticeable differences in the use of hedges and first person plural pronouns. Hedges were used more frequently in Applied Linguistics articles than Chemistry articles. This finding is in line with the findings of other research that soft disciplines are more heavily hedged than natural science and hard disciplines (Hyland, 1998; Varttala, 2001). Writers of Chemistry articles use first person plural pronoun less than writers of Applied Linguistics. Again these findings are in agreement with those obtained by Hyland (2001) who also found that writers of social science disciplines like Marketing, Business Management, Applied Linguistics to mention a few used first person plural pronouns with high frequency due to their community's expectation to adopt an impersonal and objective writing style. It appears that the main focus of writers in natural science and hard disciplines is on presenting the findings of their study not making themselves visible when putting forward their hypotheses or assumptions.

The third question attempted to find if the differences between the genders in the use of hedges and first person pronouns in the research articles in the fields of Applied Linguistics was significant. The results showed that female authors used more hedges than male authors in expressing their claims and ideas in Applied Linguistics articles. On the other hand male authors had much tendency to use possessive adjective "our" in Applied Linguistics articles than females.

The differences between the genders in the use of hedges and first person pronouns in the research articles in the fields of Chemistry were examined in the fourth question. The findings were the same as third question in that female authors used more hedges than male authors in expressing their claims and ideas and male authors had much tendency to use possessive adjective "our"in Chemistry articles than females.

The findings of this study contradicts the claim made by Lakoff (1975, as cited in Nugroho, 2002) that that women use hedges more than men do. On the other hand, in another study, Grob, Meyers, and Schuh (1997) find no significant differences between genders in their use of interruptions, hedges, and tag questions. It can be inferred that as suggested by Winn and Rubin (2001), context seemed to have the greatest effect on some aspects of gender performance.

Considering the second question, the findings revealed that in Applied Linguistics research articles lexical verbs were the most frequently used category followed by modal verbs, adverbs, adjectives, and nouns. Whereas, the most frequently used hedging device in Chemistry research articles is modal verbs followed by adverbs, lexical verbs, adjectives, and nouns. On the other hand, the most frequently used first person pronoun in Applied Linguistics and Chemistry research articles falls into "our" pronoun, followed by "we", pronoun "I" and pronoun "my". Considering the results of research question two, some previous findings are mentioned below.

Holmes (1988) found in her study of written and spoken texts that modal verbs are the most frequently occurring grammatical category followed by lexical verbs and adverbs, while adjectives and nouns are shown to be less favored grammatical classes. However, in Hyland's (1995) data consisting of research articles, lexical verbs constituted the greatest frequency. The second most frequent category was adverbs followed by adjectives, modal verbs and nouns, respectively. Farrokhi, F. \& Emami, S. (2008) found that in research articles lexical verbs are the most frequently used category followed by modal verbs, adverbs, nouns, and adjectives.

In conclusion, all the four research hypotheses were rejected in this study.

\section{Conclusion and Implication}

Lakoff (1975) believes that different and unequal status of genders is reflected by gender differences in language use. She is of the opinion that because of the low status of women, they tend to use more hedges, intensifiers, super polite forms, ... etc. in comparison to men. Results of this study showed that Lakoff's ideas regarding hedging words can be held. The findings of this study suggested that females used hedging devices more than men in their writings in both disciplines. The creation of an appropriate authorial identity by means of self-mention resources is critical for article writers in any discipline in order to present themselves as competent member of the discipline. But the fact is that writers construct their authorial identity according to specific social norms of their disciplinary communities. Researchers can make their text persuasive by following the social norms of their disciplinary communities and by projecting the authority and credibility expected by their own disciplinary communities. This can be a reason why writers of different disciplines vary in their use of personal pronoun.

The studies of gender differences in academic writing of different disciplines can help students of these disciplines be aware of how to express their stance. Making students aware of the features of a specific discourse helps them observe and apply these features in their writing. Therefore, they appear as a member of a specific discourse community. Thus, writers must employ features relevant to the specific disciplines in order to present their findings persuasively and credibly. 


\section{References}

Bloor, M. and Bloor, T. (2007). The practice of discourse analysis: an introduction. London: Hodder Arnold. Cameron, D. (1998). Is there any ketchup, Vera? : Gender, power, and pragmatics. Discourse and Society, 9, 437-55.

Cameron, D. (2005). Language, gender, and sexuality: Current issues and new directions. Applied Linguistics, 26, 482502.

Cao, Z. (2007). The effect of age and gender on the choice of address forms in Chinese personal letters. Journal of Sociolinguistics: 11, 392-407.

Climate, C. (1997). Men and women talking: The differential use of speech and language by gender. Retrieved December 14, 2006, from http://www. Google.../differential language.html+use+men+women+differentces\&hl=e.

Farrokhi, F. \& Emami, S. ( 2008 ). Hedges and boosters in academic writing : native vs. non- native research articles in applied linguistics and engineering. Journal of Applied Linguistics, 1(2), 62-98.

Halliday, M.A.K. (1985). An introduction to functional grammar. Oxford: Oxford University Press.

Herring, S. C. \& Paoolillo, J. C. (2006). Language and gender. Cambridge, U.K: Cambridge University Press.

Holmes, J. (1988). Doubt and certainty in ESL textbooks. Applied Linguistics, 9(1),20-44.

Holmes, J. (1990). Hedges and boosters in women's and men's speech. Language and Communication, 10, $185-205$.

Holmes, J. (1993). An introduction to sociolinguistics. London, UK: Longman.

Hyland, K. (1998). Boosting, hedging and the negotiation of academic knowledge. TEXT,18(3), 349-382.

Hyland, K. (2001). Humble servants of the discipline? Self-mention in research articles. English for Specific Purposes, 20, 207-226.

Hyland, K. (2002). Authority and invisibility: authorial identity in academic writing. Journal of Pragmatics, 34, 10911112.

Khalilzadeh, A. (2008). Hedging in scientific and humanistic texts. Unpublished master's thesis. University of Tabriz, Iran.

Lakoff, G. (1975). Language and woman's place. New York: Harper Colophon Books.

Mehl, M. R., \& Pennebaker, J. W. (2003). The sounds of social life: A psychometric analysis of students' daily social environments and natural conversation. Journal of Personality and Social Psychology, 84, 857-870.

Millan, E. L. (2010). Extending this claim, we propose: The writer's presence in research articles from different disciplines. Lberica, 20, 35-56.

Mulac, A. \& Lundell, T. L. (1994). Effects of gender-linked language differences in adults'written discourse: Multivariate tests of language effects. Language and Communication, 14, 299-309.

Paltridge, B. (2006). Discourse analysis: An introduction. London: Continuum.

Salager- Meyer, F. (1994). Hedges and textual communicative function in medical English written discourse. English for Specific Purposes, 13 (2), 149-170.

Schiffrin, D., Tannen, D., Hamilton, E. H., (eds.). (2001). The handbook of discourse analysis.USA, UK, Australia: Blackwell.

Trudgill, P. (1974). The social differentiation of English in Norwich. Cambridge: Cambridge University Press.

Varttala, T. (2001). Hedging in scientifically oriented discourse: Exploring variation according to discipline and intended audience. Electronic doctoral dissertation. Acta Electronica Universitatis tamperensis 138 (http://acta.fi/pdf/951-44-5195-3.pdf).

Vold, E.T. (2006). Epistemic modality markers in research articles: a cross-linguistic and cross-disciplinary study. International Journal of Applied Linguistics, 17, 61-87. 